\title{
Grafik ve Animasyon 1 Dersinde Kullanılan Mobil QuizGame Uygulamasına Yönelik Öğrenci Görüşleri*
}

\section{Student Opinions on Application of Mobile QuizGame Used in Graphic and Animation 1}

\author{
Mehmet İsmail SOLMAZ ${ }^{* *}$
}

\author{
Ali Kemal UĞUR ${ }^{* * *}$
}

Mesut ÖZONUR ${ }^{* * * * *}$

Received: 05 July 2017

Accepted: 24 May 2018

\begin{abstract}
New strategies regarding teaching and learning are being searched to increase student motivation in the education system due to the unwillingness of students. New generation students have expectations and experiences regarding education. In order to increase intrinsic motivation and participation of students in class the use of gamification, a new trend in education, is rapidly increasing. There is not much covered about student opinions regarding gamification in all the research carried out so far. The purpose of this research is to specify the student opinions about the Quizgame application. The method of research is a descriptive survey model. The participants are students in Çukurova University Adana Vocational School of Higher Education who are members of Computer Programming 1st grade. The data collecting tool in the research was a tool developed as a five point likert form with the help of the literature. In the data analysis frequency and mean values were given. During the implementation the application was downloaded to the students' mobile devices and user accounts were created. Besides questions about the course, questions about general knowledge were added to the application. When the findings regarding the scope of the research were assessed, it is determined that the students expressed opinions in the favor of the software used. They also expressed suggestions stating the software to be used in other courses.
\end{abstract}

Keywords: game application, educational software, mobile application, quizgame.

ÖZ: Eğitim sisteminde, öğrenme ve öğretmeye yönelik, öğrencilerin isteksizliklerinden dolay1, öğrencilerde motivasyonu artırmak için yeni stratejiler bulmaya çalışılmaktadırlar. Yeni nesil öğrenciler eğitimde farklı deneyim ve beklentilere sahiptir. Öğrencilerin derslerde içsel motivasyonu ve katılımını artırmak amacıyla, eğitimde yeni bir trend olan oyunlaştırma kullanımı gittikçe artış göstermektedir. Yapılan çalışmalarda oyunlaştırma hakkında öğrenci görüşlerine çok fazla yer verilmemektedir. Bu araştırmanın amacı, QuizGame uygulamasını kullanan öğrencilerin uygulamaya yönelik görüşlerini belirlemektir. Araştırma tarama modelinde betimsel bir çalışmadır. Katılımcılar, Çukurova Üniversitesi Adana Meslek Yüksekokulu Bilgisayar Programcılı̆̆g kayıtlı 1. sınıf öğrencileridir. Araştırmada veri toplama aracı olarak, literatürden de faydalanılarak beşli likert olarak geliştirilen form kullanılmıştır. Verilerin analizinde frekans ve ortalama değerleri verilmiştir. Uygulama aşamasında, öğrencilerin mobil cihazlarına uygulamanın yüklenmesi sağlanmış ve kullanıcı hesapları oluşturulmuştur. Uygulamaya ders ile ilgili seçilen sorularla birlikte genel kültür soruları da dahil edilmiştir. Araştırma kapsamında elde edilen bulgular değerlendirildiğinde, öğrencilerin kullanılan mobil uygulama hakkında olumlu görüş bildirdikleri saptanmıştır. Ayrıca diğer derslerde de kullanılması şeklinde öneriler de sunmuşlardır.

Anahtar Kelimeler: oyun uygulaması, eğitsel yazılım, mobil uygulama, quizgame.

\footnotetext{
* This research was presented at 2nd International Scientific Researches Congress on Humanities and Social Sciences.

${ }^{* *}$ Lect. Dr., Çukurova University, Adana, Turkey, misolmaz@cu.edu.tr

${ }^{* * *}$ Lect., Çukurova Univesity, Adana, Turkey, akugur@cu.edu.tr

***** Corresponding Author: Lect. Dr., Çukurova Univesity, Adana, Turkey, ozonur@cu.edu.tr
}

\section{Citation Information}

Solmaz, M. İ., Uğur, A. K., \& Özonur, M. (2018). Grafik ve Animasyon 1 dersinde kullanılan mobil QuizGame uygulamasına yönelik öğrenci görüşleri. Kuramsal Eğitimbilim Dergisi [Journal of Theoretical Educational Science], 


\section{Giriş}

Günümüzde bilim ve teknolojideki gelişmeler, eğitim alanında da yeni bir dönem başlatmıştır. Tüm ülkeler bu dönemi yakalayabilmek için bilim ve teknolojideki değişim ve gelişmeleri, öğrenme-öğretme ortamlarına uydurmak zorundadırlar. $\mathrm{Bu}$ açıdan bakıldığında eğitimi, geleneksel yöntemlerle sürdürmek olanaklı görülmemektedir (Uğur, 2010). Geleneksel öğretim yöntemleri pek çok öğrenci tarafından etkisiz ve sıkıcı olarak algılanmaktadır. Öğretmenler sürekli olarak yeni öğretim yaklaşımları aramaya devam ederken, günümüz okullarının öğrencilerin motivasyonu ve katılımı ile ilgili büyük sorunlarla karşı karşıya olduğu konusunda herkes hem fikirdir. Öğretim yöntemleri, yeni neslin ihtiyaçları ve teknolojik gelişmelere bağlı olarak, farklı yöntem ve tekniklere ve yeniliklere ihtiyaç duymaktadır (Sarı \& Altun, 2016). Teknoloji, bireyin öğrenmesini şekillendirmede kolaylık getirirken kalıcılığı da sağlamada eğitimdeki yerini almaktadır. Bir tarafta teknolojiyi yeni görenler, kullananlar varken diğer taraftan teknolojinin içinde doğan ve büyüyen yeni bir nesil ortaya çıkmıştır (Sarıtaş \& Yıldız, 2015). Bu nesil, dijital yerliler (digitalnatives), net vatandaşları (netizens) gibi farklı isimlerle de anılan milenyum nesli teknolojiyle doğan, teknolojiyi günlük hayatın sıradan bir parçası olarak yorumlayan ve içselleştiren bir nesildir (Bozkurt \& Kumtepe, 2014).

Bu bağlamda yeni nesil öğrencilerin yoğun olarak hem bilgi kaynağı ve hem de ilgi duydukları akıllı cep telefonlarının kullanımı öne plana çıkmaktadır. Çünkü zamanlarının çoğunu akı1lı telefonları kullanarak harcayan öğrenciler, ders çalışma, ödev yapma, vb. etkinliklere daha az zaman ayırdıkları belirlenmiştir (Gümüş \& Örgev, 2015).

Telefon kullanımına ayrılan zamanın büyük bir oranını ise mobil oyunlar oluşturmaktadır. Öğrencilerin mobil oyunlara olan yoğun ilgisi, eğitim öğretime olan ilgiyi azaltmaktadır. Özellikle öğretmenlerin öğretim etkinliklerindeki en büyük sorunlardan bir tanesi öğrencilerin yeterli miktarda motive edilememesi ve buna bağlı olarak öğrencilerin öğretim ortamına dahil olamamalarıdır. Prensky (2004) 21. yüzyılda eğitimde yaşanacak en büyük ilerlemenin ancak eğitim ortamlarını sıkıcı hale getiren unsurların ortadan kaldırılarak öğrenmenin eğlenceli ve ilgi çekici hale getirilmesiyle sağlanacağını ifade etmiştir. Öğrencileri öğrenmeye teşvik edebilmek için, motive olmalarını sağlayan öğrenme faaliyetlerine yer verilmesi gerekmektedir. Bu bağlamda öğrencilerin bu kadar ilgisini çeken ve zaman ayırdıkları oyunların oyun dışı alanlarda kullanılması fikri ortaya çıkmıştır. Oyunlaştırma (Gamification) olarak adlandırılan bu fikir; oyun olmayan içerik ve ortamlarda problemlerin çözümü, motivasyon ve bağlılığın artırılması için oyun mekanikleri ve dinamikleri ile oyun tasarım tekniklerinin kullanılmasıdır (Werbach \& Hunter, 2015). Yapılan araştırmalarda oyunlaştırma kavramı; kullanıcıyla iletişim kurmak ve problem çözmede oyunsal düşünme süreci ve mekaniği (Zichermann \& Linder, 2010), oyun kapsamında olmayan oyun tasarımı öğelerinin kullanılması (Deterding ve diğerleri, 2011), insanlarla iletişime geçmek, olayları güdülemek, öğrenmeyi aşılamak ve problemleri çözmek amacıyla oyun-tabanlı mekanizmaları kullanmak ve oyunsal düşünmek (Kapp, 2012) olarak tanımlanmaktadır.

Yaygın kullanımı ise lider tablosu, puanlama, madalya gibi oyun öğelerinin kullanıcı bağlılığı sağlama ve motivasyonu arttırma amaçlı olarak herhangi bir alana entegre edilmesi şeklindedir (Akt. Ar, 2016; Nicholson, 2012). Oyunlaştırmanın amac1; bireylerin oyun tekniklerini kullanarak sorumluluklarını artırmak ve ulaşılmak istenilen 
amacı daha dikkat çekici ve ulaşılması gereken bir görev haline getirmektir (Fiş Erümit, 2016).

Son yıllarda oyunlaştırma, iş, pazarlama, kurumsal yönetim, sağlıklı yaşam ve ekoloji alanlarında hızlı bir şekilde benimsenmiştir. Bu, kullanıcıların davranışlarını istenen yönde şekillendirme potansiyeline dayanmaktadır. Oyunlaştırma ilk örneklerini pazarlama alanında uçuş milleri toplama gibi müşteri sadakat uygulamalarıyla göstermiş Foursquare gibi dijital uygulamaların başarısı ile yaygınlaşmaya başlamıştır. Bay ve Fitocracy gibi siteler, Codeacademy.com ve khanacademy.org gibi çevrimiçi eğitim siteleri kullanıcıları daha iyi etkileşime sokmak için oyun öğelerini kullanmakta ve kullanıcılar arasındaki dostça rekabeti teşvik etmektedir.

Oyunlaştırma kavramı, eğitsel veya ciddi oyunlardan farklıdır. Eğitimde, oyunları öğrenme araçları olarak kullanma, oyunların öğretme yetenekleri ve aslında sadece bilgiyi değil aynı zamanda problem çözme, iş birliği ve iletişim gibi önemli becerileri de güçlendirdikleri için gelecek vaat eden bir yaklaşımdır. Oyunların dikkat çekici ve motive edici gücü bulunmaktadır. Oyunlar, kazanma hırsından dolayı, genellikle insanları kendileri ile etkileşime sokmaya teşvik etmek için birtakım mekanizmaları kullanırlar. Bununla birlikte öğretim için, ilgi çekici ve tam donanımlı bir oyun oluşturmak, genellikle oyun tasarımcısı tarafından seçilen tek bir öğrenim hedefi grubunu hedef alırken zor, zaman alıcı ve masraflıdır (Kapp, 2012). Bununla birlikte eğitimin oyunlaştırılması, etkili bir şekilde sınıf katılımı, bazı teknik altyapı ve uygun pedagojik entegrasyonu gerektirir. Gelişmiş, tasarlaması maliyetli ve zor olan oyunlar yerine, "oyunlaştırma" yaklaşımı, öğrencilerin katılımını ve motivasyonunu artırmak için çok uygun bir yol olarak görülmektedir.

Eğitimde oyunlaştırmanın kullanımı, oyun öğelerinin öğrenciler üzerinde oluşturduğu rekabet ve eğlencenin katkısıyla olumlu etkiler yaratarak motivasyonu, bağlanmayı ve üretkenliği arttırmak üzere temellendirilir. Oyun tasarımının, eğitim sürecine aktarılarak öğrencilerin dikkat ve motivasyonunun artırılması ile, başarılarının ve derse yönelik tutumlarının olumlu yönde etkilenmesi ise eğitimin oyunlaştırılması olarak tanımlanabilir (Yıldırım, 2016).

Werbach ve Hunter (2012) eğitimin oyunlaştırılması sürecinde belirgin bir sürecin işletilmesi gerektiğini ve bu sürecin 6 adımda yapılabileceğini belirtmektedir. Bu adimlar:
a) Hedeflerini tanımla
b) Hedef davranışları tanımla
c) Oyuncuları tanımla
d) Etkinlik döngüleri tasarla
e) Eğlenceyi unutma!
f) Uygun araçları yerleştir

şeklinde ifade edilmektedir. Hedeflerin tanımlanması aşamasında; oyunlaştırma kapsamında davranış değişikliğine sebep olan görevler belirlenmelidir. Örneğin, oyunlaştırma sürecinin, akademik başarıyı artırmak için mi, derse katılımı sağlamak için mi, iş birliği ve araştırma yaparak öğrenme becerisini geliştirmek için mi geliştirileceği ortaya konmalıdır. Daha sonra; hedef davranışları tanımlama basamağında kazanımlar netleştirilmeli ve sıralanmalıdır. Hedeflerin tanımlanmasının ardından oyuncular yani öğrenciler tanımlanmalıdır. Yani öğrencilerin kişilik özellikleri oyuncu tiplerinden 
hangisine denk gelmektedir. "Arkadaşları ile eğlenceli zaman geçirmek isteyen sosyaller mi, oyun içi hedeflere odaklanan başarıcılar mı, arkadaşlarını yenmek için oynayan katiller mi yoksa oyun yapısını çözmeye çalışan kâşifler mi sınıfta çoğunluğu oluşturuyor?" sorunun cevabı aranmalıdır. Ya da süreçte her oyuncu tipine hitap eden etkinliklere yer verilerek genel bir tasarıma da gidilebilir. $\mathrm{Bu}$ durumda yine de öğrencilerin yaşları ve hazırbulunuşluk düzeyleri sürecin tasarlanmasında önem arz etmektedir. Son olarak da etkinlikler tasarlanacak ve uygun araçlar kullanılacaktır (Akt. Yildırım, 2016; Werbach \& Hunter, 2012).

Özellikle eğitimin vazgeçilmez bir unsuru haline gelen oyunla eğitim, eğitimcilerin hedeflerine ulaşmasında kullandıkları en etkili araçlardan biri olmaktadır. Okulların çoğunda oyun ve oyun benzeri unsurların zaten bulunduğu bilinmektedir. Oyunlar üzerine yapılan araştırmalar, eğitim alanında insanların motivasyon ve bağlılıklarını desteklemek için oyunlaştırmanın yüksek bir potansiyele sahip olduğunu ortaya çıkarmıştır (Fiş Erümit, 2016).

$\mathrm{Bu}$ bağlamda oyunlaştırılmış öğrenme ortamlarının daha etkili öğrenmeler sağlayacağ1, öğrencilerin öğrenme sürecinde akış düzeylerini artırabileceği ve öğrencilerin derse karşı motivasyonlarını olumlu yönde etkileyeceği düşünülmektedir.

Yapılan araştırmalarda oyunlaştırma temelli öğretime dayalı olarak geliştirilen uygulamaların ve bu uygulamalarla ilgili deneysel çalışmaların yetersiz olduğu tespit edilmiştir.

$\mathrm{Bu}$ araştırmada, "Önlisans düzeyinde, Grafik Animasyon 1 dersinde, oyunlaştırma temelli öğretime dayalı olarak geliştirilen QuizGame uygulamasına yönelik öğrenci görüşleri nelerdir” sorusuna yanıt aranacaktır.

\section{Yöntem}

$\mathrm{Bu}$ araştırmada Grafik ve Animasyon 1 dersinde kullanılan mobil QuizGame uygulamasına ilişkin mevcut durumu ortaya çıkarmak amaçlanmaktadır. Bu doğrultuda araştırma, tarama modelinde betimsel bir çalışmadır.

\section{Çalışma Grubu}

Araştırmanın çalışma grubu Çukurova Üniversitesi Adana Meslek Yüksekokulu Bilgisayar Programcılığı 1. sınıf Grafik ve Animasyon 1 dersine kayıtlı 30 öğrenciden oluşmaktadır. Öğrenciler 18-20 yaş aralığında olup, 13 kadın, 17 erkek olarak yer almaktadir.

\section{Veri Toplama Araçları ve Verilerin Toplanması}

Veriler, öğrenci görüşlerini belirlemek amacıyla literatürden yararlanılarak beşli likert olarak geliştirilen form aracılığıyla toplanmıştır (Ateş, 2011; Kaya, 2005; Şahin\&Yıldırım, 1999). Form "Çok İyi”, "İyi”, “Orta”, "Zayıf” ve "Çok Zayıf” şeklinde derecelendirilmiştir. Form, içerik, kurulum ve kullanım özellikleri ve uyumluluk başlıkları altında toplanan 22 madde ve her başlık için önerilerini isteyen birer açık uçlu sorudan oluşmaktadır. Form sorularının uygunluğu bilgisayar ve öğretim teknolojileri, eğitim programları ve öğretim ve bilgisayar programcılığı alanından uzman görüşleri alınarak son haline getirilmiştir. 


\section{Verilerin Analizi}

Verilerin analizinde, bu çalışmada, Grafik ve Animasyon 1 dersinde kullanılan mobil QuizGame uygulamasına ilişkin mevcut durumu ortaya çıkarmayı amaçlayan betimsel bir çalışma olması nedeni ile ölçme sonuçlarının görülme sıklıklarını göstermek için frekans değerleri verilmiştir. Ayrıca frekans dağılımları ile yapılan betimleme işleminin yanında betimsel istatistik olarak ortalama değerleri de verilmiştir.

\section{Uygulama Süreci}

Grafik ve Animasyon 1 dersinin uygulama aşamasında, öğrencilerin kullanabilecekleri uygulamanın mobil cihazlara yüklenmesi sağlanmış ve kullanıcı hesapları oluşturulmuştur. Uygulamaya ders ile ilgili seçilen sorulara ilaveten genel kültür soruları da eklenmiştir. Derse ait sorular uzman görüşleri alınarak değerlendirilip uygulamaya yüklenmiştir. Uygulama sonunda geliştirilen form aracılığı ile öğrencilerin görüşleri alınmıştır.

Eğitimlerin daha etkili olmasını sağlamak amacıyla Pixofun tarafından geliştirilen QuizGame, öncelikle öğrencilerin eğitim içeriğini hatırlamalarını sağlayan, standart sınav yöntemleriyle bütünleştiren, oyunlaştırma tekniklerini ve mekaniklerini kullanan oyunlaştııılmış sınav aracıdır (Pixofun, 2016). Eğlence ile eğitimi birleştirerek bir oyun modülü olarak sunan QuizGame, Quiz, Duello, Turnuva modülleri en ilgi çekici olan modüllerinden bazılarıdır. Deney grubuna uygulanan mobil uygulama ile öğrencilerin eğlenceli bir ortamda soru çözmeleri ve eğlenmeleri sağlanmıştır.

Ayrıca, yönetici kontrol paneli aracılı̆̆ı ile uygulamaya yeni sorular girilebilmekte ve/veya var olanlar değiştirilebilmektedir. Her ortamdan erişilebilir özelliğe sahip olması oyunun zamandan bağımsız olarak oynanmasına da olanak sağlamaktadır.

Şekil 1. QuizGame Uygulamasından Örnek Ekran Görüntüleri
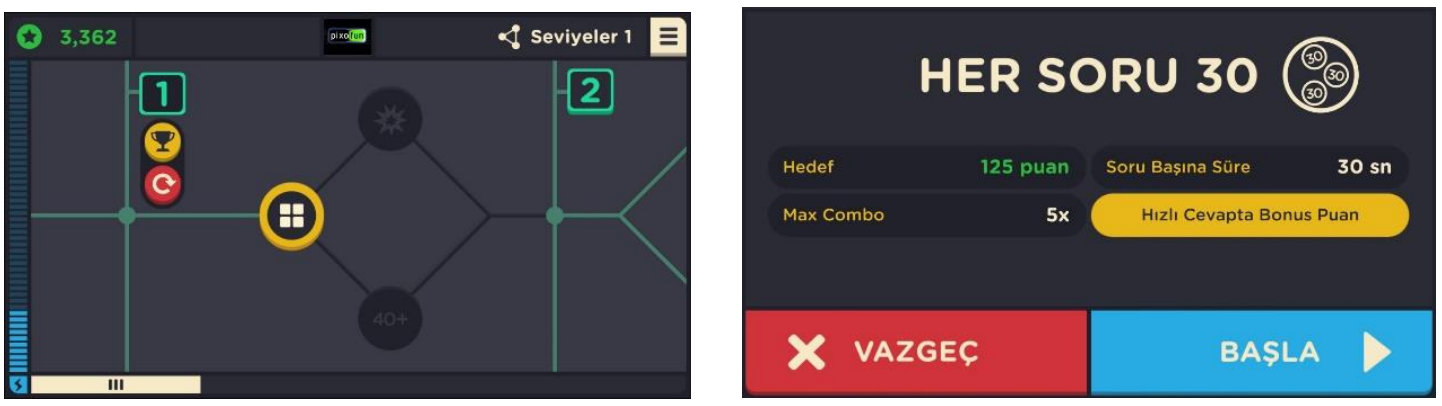


\section{Bulgular}

\section{İçerik ile İlgili Bulgular}

Tablo 1

İçerik ile İlgili Bulgular

\begin{tabular}{|c|c|c|c|c|c|c|}
\hline \multicolumn{2}{|c|}{ İçerik Açısından } & \multirow{2}{*}{$\begin{array}{l}\text { Çok } \\
\text { İyi } \\
20\end{array}$} & \multirow{2}{*}{$\begin{array}{l}\text { İyi } \\
8\end{array}$} & \multirow{2}{*}{$\begin{array}{l}\text { Orta } \\
2\end{array}$} & \multirow{2}{*}{$\begin{array}{l}\text { Zayif } \\
-\end{array}$} & \multirow{2}{*}{$\begin{array}{l}\text { Çok } \\
\text { Zayıf } \\
-\end{array}$} \\
\hline 1 & Yazılım ders konularının öğrenimini destekliyor. & & & & & \\
\hline 2 & Yazılım, öğrencinin içeriğe dikkatini çekiyor. & 16 & 6 & 7 & 1 & - \\
\hline 3 & Yazılım içeriği öğrenci hedef kitlesine uygun & 16 & 10 & 2 & 2 & - \\
\hline 4 & Oyundaki rekabetin motivasyona etkisi & 14 & 10 & 3 & 2 & 1 \\
\hline 5 & $\begin{array}{l}\text { Yazılımda kullanılan çoklu ortam öğeleri (ses, video, } \\
\text { metin, animasyon, simülasyon, resim, vb.) oyunun } \\
\text { amacına uygun nitelikte ve yeterli sayıdadır. }\end{array}$ & 11 & 9 & 4 & 4 & 2 \\
\hline 6 & $\begin{array}{l}\text { Yazılımın içeriğinde çoklu ortam öğeleri kullanılarak } \\
\text { öğrenciler için yeteri düzeyde etkileşim } \\
\text { sağlanmaktadır. }\end{array}$ & 11 & 11 & 6 & 2 & - \\
\hline 7 & $\begin{array}{l}\text { Kullanılan çoklu ortam öğeleri, genel tasarım ilkeleri } \\
\text { dikkate alınarak hazırlanmıştır. (renk, denge, boyut, } \\
\text { vs.). }\end{array}$ & 9 & 12 & 5 & 3 & 1 \\
\hline 8 & Türkçe doğru, güzel ve etkili kullanılıyor. & 19 & 8 & 1 & 1 & 1 \\
\hline
\end{tabular}

Tablo 2

İçerik ile İlgili Betimsel İstatistik

\begin{tabular}{|c|c|c|c|}
\hline \multicolumn{2}{|c|}{ İçerik Açısından } & \multirow{2}{*}{$\begin{array}{l}N \\
30\end{array}$} & \multirow{2}{*}{$\begin{array}{l}X \\
4.60\end{array}$} \\
\hline 1 & Yazılım ders konularının öğrenimini destekliyor. & & \\
\hline 2 & Yazılım, öğrencinin içeriğe dikkatini çekiyor. & 30 & 4.23 \\
\hline 3 & Yazılım içeriği öğrenci hedef kitlesine uygun & 30 & 4.33 \\
\hline 4 & Oyundaki rekabetin motivasyona etkisi & 30 & 4.13 \\
\hline 5 & $\begin{array}{l}\text { Yazılımda kullanılan çoklu ortam öğeleri (ses, video, metin, animasyon, } \\
\text { simülasyon, resim, vb.) oyunun amacına uygun nitelikte ve yeterli } \\
\text { sayıdadır. }\end{array}$ & 30 & 3.77 \\
\hline 6 & $\begin{array}{l}\text { Yazılımın içeriğinde çoklu ortam öğeleri kullanılarak öğrenciler için } \\
\text { yeteri düzeyde etkileşim sağlanmaktadır. }\end{array}$ & 30 & 4.03 \\
\hline 7 & $\begin{array}{l}\text { Kullanılan çoklu ortam öğeleri, genel tasarım ilkeleri dikkate alınarak } \\
\text { hazırlanmıştır. (renk, denge, boyut, vs.). }\end{array}$ & 30 & 3.83 \\
\hline 8 & Türkçe doğru, güzel ve etkili kullanılıyor. & 30 & 4.43 \\
\hline
\end{tabular}


Tablo 1'de öğrenciler içerik başlı̆ğ altında uygulamanın özellikle "ders konularının öğrenimi desteklemesi”, Türkçe'nin doğru, güzel ve etkili kullanılması”, "içeriğe dikkat çekmesi" ve "hedef kitleye uygun olması" maddeleri için çoğunlukla "çok iyi” değerlendirmesi yapmışlardır. Böylelikle kullanılan uygulamanın içerik açısından öğrencilerin genel olarak beklentilerini karşıladığı söylenebilir. Tablo 2'deki her maddeye ait ortalamalarda bunu destekler niteliktedir. "Ders konularının öğrenimi desteklemesi" ( $\mathrm{X}=4.60)$ maddesi en yüksek ortalamaya sahip olurken "kullanılan çoklu ortam öğeleri oyunun amacına uygun nitelikte ve yeterli sayıda" olduğunu sorgulayan madde ise en düşük ortalamaya sahiptir $(X=3.77)$. "Çoklu ortam öğeleri" maddesi ortalamasının en düşük olması, kullanılan uygulamadaki sorulara görsel materyal eklenememesi özelliği nedeni ile olduğu söylenebilir. Yapılan olumlu değerlendirmelerin yanında az sayıda öğrenci $(\mathrm{N}=3)$ mobil QuizGame uygulamasının seviyeleri arasındaki geçiş kurallarına dair yeniden bir düzenlemeye ihtiyaç olduğunu da belirtmişlerdir.

\section{Kurulum ve Kullanım Özellikleri ile İlgili Bulgular}

Tablo 3

Kurulum ve Kullanım Özellikleri İle İlgili Bulgular

\begin{tabular}{|c|c|c|c|c|c|c|}
\hline \multicolumn{2}{|c|}{ Kurulum ve Kullanım Özellikleri Açısından } & \multirow{2}{*}{$\begin{array}{l}\text { Çok } \\
\text { İyi } \\
16\end{array}$} & \multirow{2}{*}{$\begin{array}{l}\text { İyi } \\
6\end{array}$} & \multirow{2}{*}{$\begin{array}{l}\text { Orta } \\
7\end{array}$} & \multirow{2}{*}{$\begin{array}{l}\text { Zayıf } \\
1\end{array}$} & \multirow{2}{*}{$\begin{array}{l}\text { Çok } \\
\text { Zayıf } \\
-\end{array}$} \\
\hline 9 & $\begin{array}{l}\text { Yazılım kullanım kılavuzuna bakılmadan } \\
\text { kolaylıkla kullanılabiliyor. }\end{array}$ & & & & & \\
\hline 10 & Kullanıcı yazılımın tanıtım kısmını geçebiliyor. & 17 & 8 & 4 & 1 & - \\
\hline 11 & $\begin{array}{l}\text { Kullanıcı istediği yerden yazılıma } \\
\text { başlayabiliyor ve sonradan aynı yerden } \\
\text { kolaylıkla devam edebiliyor. }\end{array}$ & 12 & 7 & 5 & 3 & 3 \\
\hline 12 & $\begin{array}{l}\text { Kullanıcı istediğinde yazılımın ayarlarını (ses, } \\
\text { görüntü, vb.) değiştirebiliyor. }\end{array}$ & 10 & 8 & 8 & 1 & 3 \\
\hline 13 & $\begin{array}{l}\text { Yazılım kullanıcı komutlarına kısa sürede } \\
\text { cevap veriyor. }\end{array}$ & 14 & 6 & 8 & 1 & 1 \\
\hline 14 & $\begin{array}{l}\text { Yazılımın kullanımı ile ilgili gerekli } \\
\text { yönlendirmeler yazılım içerisinde bulunuyor. }\end{array}$ & 19 & 6 & 4 & 1 & - \\
\hline 15 & $\begin{array}{l}\text { Yazılımda yeterli düzeyde bir puanlama } \\
\text { sistemi var. }\end{array}$ & 13 & 10 & 4 & 2 & 1 \\
\hline 16 & $\begin{array}{l}\text { Yazılımın kullanıma hazırlık süresi yeterince } \\
\text { kısadır. }\end{array}$ & 16 & 4 & 7 & 3 & - \\
\hline 17 & $\begin{array}{l}\text { Yazılımın ağ ortamında ağ bilgisine çok ihtiyaç } \\
\text { duyulmadan kullanılabiliyor. }\end{array}$ & 9 & 11 & 5 & 1 & 4 \\
\hline 18 & $\begin{array}{l}\text { Yazılımda kullanılan çoklu ortam öğeleri } \\
\text { yüksek kalitede ve güncel bilgisayar } \\
\text { teknolojisinin imkânlarını kullanıyor. }\end{array}$ & 16 & 9 & 2 & 3 & - \\
\hline 19 & $\begin{array}{l}\text { Oyunun devamlılığı için kullanıcılara günlük } \\
\text { bildirimler göndermesi }\end{array}$ & 16 & 6 & 4 & 3 & 1 \\
\hline 20 & $\begin{array}{l}\text { Yazılım ekranındaki tüm öğelerin işlevleri açık } \\
\text { ve anlaşılırdır. }\end{array}$ & 20 & 5 & 1 & 1 & 3 \\
\hline
\end{tabular}


Tablo 4

Kurulum ve Kullanım Özellikleri İle İlgili Betimsel İstatistik

\begin{tabular}{|c|c|c|c|}
\hline \multicolumn{2}{|c|}{ Kurulum ve Kullanım Özellikleri Açısından } & \multirow{2}{*}{$\begin{array}{l}N \\
30\end{array}$} & \multirow{2}{*}{$\begin{array}{l}X \\
4.23\end{array}$} \\
\hline 9 & Yazılım kullanım kılavuzuna bakılmadan kolaylıkla kullanılabiliyor. & & \\
\hline 10 & Kullanıcı yazılımın tanıtım kısmını geçebiliyor. & 30 & 4.37 \\
\hline 11 & $\begin{array}{l}\text { Kullanıcı istediği yerden yazılıma başlayabiliyor ve sonradan aynı } \\
\text { yerden kolaylıkla devam edebiliyor. }\end{array}$ & 30 & 3.73 \\
\hline 12 & $\begin{array}{l}\text { Kullanıcı istediğinde yazılımın ayarlarını (ses, görüntü, vb.) } \\
\text { değiştirebiliyor. }\end{array}$ & 30 & 3.70 \\
\hline 13 & Yazılım kullanıcı komutlarına kısa sürede cevap veriyor. & 30 & 4.03 \\
\hline 14 & $\begin{array}{l}\text { Yazılımın kullanımı ile ilgili gerekli yönlendirmeler yazılım } \\
\text { içerisinde bulunuyor. }\end{array}$ & 30 & 4.43 \\
\hline 15 & Yazılımda yeterli düzeyde bir puanlama sistemi var. & 30 & 4.07 \\
\hline 16 & Yazılımın kullanıma hazırlık süresi yeterince kısadır. & 30 & 4.10 \\
\hline 17 & $\begin{array}{l}\text { Yazılımın ağ ortamında ağ bilgisine çok ihtiyaç duyulmadan } \\
\text { kullanılabiliyor. }\end{array}$ & 30 & 3.67 \\
\hline 18 & $\begin{array}{l}\text { Yazılımda kullanılan çoklu ortam öğeleri yüksek kalitede ve güncel } \\
\text { bilgisayar teknolojisinin imkânlarını kullanıyor. }\end{array}$ & 30 & 4.27 \\
\hline 19 & Oyunun devamlılığı için kullanıcılara günlük bildirimler göndermesi & 30 & 4.10 \\
\hline 20 & Yazılım ekranındaki tüm öğelerin işlevleri açık ve anlaşılırdır. & 30 & 4.27 \\
\hline
\end{tabular}

Tablo 3'te öğrenciler kurulum ve kullanım özellikleri başlığı altında uygulamanın özellikle kullanımı ile ilgili "gerekli yönlendirme" konusunda ve "ekran öğelerinin anlaşılırlığı” maddeleri için çoğunlukla "çok iyi” değerlendirmesi yapmışlardır. Değerlendirme formunda yer alan her maddeye ait ortalamaların da iyi seviyede olması öğrenci görüşlerini desteklemektedir (Tablo 4). Değerlendirme formunda "yönlendirme" ile ilgili maddesi $(X=4.43)$ en yüksek ortalamaya sahip iken "ağ ortamı bilgisi" gerekliliğini sorgulayan madde ise en düşük ortalamaya sahiptir $(X=3.67)$. "A $\breve{g}$ ortamı bilgisi" maddesi ortalamasının en düşük olmasının nedeni, kullanılan uygulamanın sürekli internet bağlantısı gerektirmesi ile açıklanabilir. Öğrenciler tarafından yapılan olumlu değerlendirmelerin yanısıra az sayıda öğrenci $(\mathrm{N}=2)$ kullanılan mobil uygulama içinde öğrenci-öğrenci, öğrenci-yönetici şeklinde mesajlaşma firsatı sağlaması gerektiğini ifade etmişlerdir. 


\section{Uyumluluk ile İlgili Bulgular}

Tablo 5

Uyumluluk İle İlgili Bulgular

\begin{tabular}{|c|c|c|c|c|c|c|}
\hline \multicolumn{2}{|c|}{ Uyumluluk Açısından } & \multirow{2}{*}{$\begin{array}{l}\text { Çok } \\
\text { İyi } \\
19\end{array}$} & \multirow{2}{*}{$\begin{array}{c}\text { İyi } \\
6\end{array}$} & \multirow{2}{*}{$\begin{array}{l}\text { Orta } \\
5\end{array}$} & \multirow{2}{*}{$\begin{array}{l}\text { Zayıf } \\
-\end{array}$} & \multirow{2}{*}{$\begin{array}{l}\text { Çok } \\
\text { Zayıf } \\
-\end{array}$} \\
\hline 21 & Yazılımın kullanılan ortama uygunluğu & & & & & \\
\hline 22 & Uygulama için yönlendirmelerin yeterliliği & 16 & 8 & 4 & 2 & - \\
\hline
\end{tabular}

Tablo 6

Uyumluluk İle İlgili Betimsel İstatistik

\begin{tabular}{llcc}
\hline Uyumluluk Açısından & $N$ & $X$ \\
\hline 21 & Yazılımın kullanılan ortama uygunluğu & 30 & 4.45 \\
22 & Uygulama için yönlendirmelerin yeterliliği & 30 & 4.24
\end{tabular}

Tablo 5'e bakıldığında öğrenciler, mobil QuizGame uygulamasının uyumluluk özellikleri başlığı altında "ortama uygunluğu” ve “yönlendirme yeterliliği” maddeleri için çoğunlukla "çok iyi”" değerlendirmesi yapmışlardır. Öğrencilerin değerlendirme formunda yer alan maddelere ait ortalamaların da iyi seviyede olduğu da Tablo 6'de verilmiştir. Elde edilen ortalamaların yüksek olması, öğrencilerin bu tür uygulamaları kurma ve kullanma konusundaki deneyimlerinin çok olması ile açıklanabilir.

\section{Sonuç ve Tartışma}

Araştırma kapsamında mobil QuizGame uygulaması içerik, kurulum ve kullanım özellikleri ve uyumluluk başlıkları altında değerlendirilmiştir.

İçerik başlığı altında elde edilen bulgulara dayalı olarak, öğrenciler kullanılan mobil uygulama hakkında olumlu görüşler bildirmişlerdir. $\mathrm{Bu}$ değerlendirmeye bağlı olarak ders konularını desteklemesi, içeriğe dikkat çekmesi, hedef kitleye uygun olması, rekabetin motivasyona olan etkisi, kullanılan çoklu ortam nesnelerinin yeterli ve etkileşimli olması gibi konularda mobil uygulamanın istenen düzeyde olduğu sonucu çıkarılabilir. Ancak bu değerlendirmelerin yanında az sayıdaki öğrencinin mobil QuizGame uygulamasının seviyeleri arasındaki geçiş kuralları ile ilgili bazı değişiklikler yapılması gerektiğini belirtmişlerdir. Bunun nedeni olarak uygulamanın herhangi bir seviyede bir öğrencinin başarısız olması durumunda bir üst seviyeye geçişe imkân tanımaması söylenebilir.

Kurulum ve kullanım özelliklerinden elde edilen bulgulara göre, öğrenciler olumlu yönde değerlendirmede bulunmuşlardır. Kullanım kolaylığı, kullanıcının uygulamada istediği yerden başlayıp devam etmesi, bazı ayarları değiştirebilmesi, uygulamanın hızı, kullanıcıyı yönlendirme, puanlama sistemine sahip olması, ağ bilgisine ihtiyaç duymaması, kullanıcılara günlük bildirimler göndermesi, işlevlerin açık ve anlaş1lır olması gibi konularda mobil uygulamanın kurulum ve kullanım özellikleri bakımından talepleri karşıladığı sonucu söylenebilir. Tüm bunların dışında az sayıda 
öğrenci kullanılan mobil uygulama içinde yeterli düzeyde iletişim/mesajlaşma olmadığını belirtmişlerdir.

Uyumluluk özelliklerinden elde edilen bulgular 1şı̆̆ında, öğrenciler değerlendirmelerinde olumlu yönde görüş belirtmişlerdir. Mobil QuizGame uygulamasının ortama uygunluğu ve yönlendirmelerin yeterliliği konularında yeterli düzeyde olduğu sonucuna ulaşılmıştır.

$\mathrm{Bu}$ çalışmadan elde edilen bulgular incelendiğinde, mobil bir cihaz üzerinden, eğitimin oyunlaştırılarak sunulmasının rekabet ortamı oluşturduğu, performans grafikleri ve liderlik tablolarının öğrenciler tarafından ilginç ve dikkat çekici bulunduğu ve derse karşı motivasyon bakımından da olumlu etkiler gösterdiğine dair öğrenci görüşleri elde edilmiştir. Bu sonuca öğrencilerin QuizGame'e PC'den, internet tarayıcısı üzerinden, iOS/Android telefon ve tabletlerden erişilebilmekte, ayrıca herhangi bir cihazda kaldığı yerden, başka bir cihazla devam edebilmesinin etkisi olduğu söylenebilir.

Literatürdeki benzer çalışmalar incelendiğinde (Glover, 2013; Oblinger \& Oblinger, 2005; Pedró, 2006; Prensky, 2001) günümüz öğrencilerinin öğretim ortamlarında, oyunlaştırma temelli uygulamalara hazır olduğu ve bu konuda özellikle ilgi ve motivasyon bakımından olumlu dönütler verdikleri görülmektedir.

Benzer şekilde, Hamari, Koivisto ve Sarsa (2014), Harrold (2015), De-Marcos vd. (2014), Polat (2014) ve Yıldırım (2016) da araştırmalarında eğitimde oyunlaştırmanın öğrenci tutumu üzerinde olumlu yönde etkiye sahip olduğu sonucuna ulaşmışlardır. Eğitimde oyunlaştırma uygulamalarının kullanılması bu bağlamda önemli görülmektedir.

$\mathrm{Bu}$ çalışma sınırlı içerik ve süre kullanılarak gerçekleştirilmiştir. Bundan sonraki çalışmalarda içeriğin ve sürenin daha geniş tutulması, öğrenci kitlesinin çoğaltılması rekabet ve uygulanabilirlik açısından daha faydalı sonuçlar verebilir. Öğrencilerden alından dönütlerde de diğer derslerde de kullanılması yönündeki önerileri de bu yöndeki görüşü desteklemektedir. 


\section{Summary}

Purpose and Significance: In recent years, changes in science and technology have also started a new era in education. All countries have to adapt the developments achieved in science and technology to learning-teaching environments in order to keep up with this era. From this point of view it doesn't seem possible to continue education with traditional methods (Uğur, 2010). Traditional teaching methods are perceived as ineffective and boring by many students. As teachers continue to look for new approaches in teaching, everyone agrees that today's schools face major challenges concerning motivation and participation of students. Teaching methods require renewal and different methods and techniques depending on technological developments and the changing expectations of new generations (Sar1 \& Altun, 2016). While technology takes its place in shaping the learning of the individual by providing materials that provide convenience in education it also takes its place in providing permanence. On one side there are people who are new to technology and using it there is a growing generation on the other side which is born into technology. (Sarıtaş \& Yıldız, 2015). This generation is a generation born into millennial generation technology, also known as digital natives or netizens, a generation that interprets and internalizes technology as an ordinary part of everyday life (Bozkurt \& Kumtepe, 2014).

In this context, the use of smart mobile phones is especially prominent as a source of information and interest for the new generation of students. It is determined that students spend most of their time using this type of telephone and spend less time for for activities such as studying, doing homework etc... (Gümüş \& Örgev, 2015).

Mobile games are a large part of the time spent on phone use. The intense interest of students in mobile games has reduced the affinity to education. Especially one of the biggest problems in teaching activities performed by teachers is that students cannot be motivated in sufficient quantity and accordingly students cannot be included in the teaching environment. Prensky (2004) stated that the greatest advancement in education in 21 st century will be achieved only by removing the elements that make learning environments boring and making learning fun and engaging. In order to encourage students to learn, learning activities that motivate them must be included. In this context, as an idea to be considered using games, which students are so attracted to and spend their times on, have come out. This idea, which is called Gamification, is the use of game mechanics, dynamics and game design techniques for solving problems, creating motivation and increasing connection in non-game environments (Werbach \& Hunter, 2015). The concept of gamification in literature is defined as, communicating with the user and to solve the problem of the gameful thinking process and mechanics, (Zichermann \& Linder, 2010), using of game design elements that are not in the game scope (Deterding et al., 2011), using game-based mechanisms to communicate with people, motivate events, overcome learning and solve problems and think gamefully (Kapp, 2012). The aim of gamification; To increase the responsibilities of the individuals with their play techniques and to make them a more interesting and targeted task that is desired to be achieved (Fiş Erümit, 2016).

The concept of gamification is different from educational or serious games. In education, using games as learning tools is a promising approach because it also enhances the skills of teaching games and not only knowledge but also important skills such as problem solving, collaboration and communication. Games are attention 
grabbing and have motivating power. Thanks to the ambition of winning, games usually use a number of mechanisms to encourage people to interact with them. However, it is hard, time consuming and expensive to prepare a fully equipped, attention grabbing game for education that generally aims at only one learning goal (Kapp, 2012). Meanwhile gamification requires effective class participation, some technical background and appropriate pedagogical integration. It is seen as a very convenient way to use gamification instead of games, which are costly and hard to design, in order to increase student participation and motivation.

The use of gamification in education is based on increasing motivation, addiction and productivity with the help of positive effects coming from the competition and fun that the game factors create on students. Increasing attention and motivation of the students by transferring game design to the education process thus influencing students attitudes towards the achievements and lessons positively, can be defined as the gamification of the education (Y1ldırım, 2016).

Education with game, which is an indispensable element of education in particular, is one of the most effective tools that educators use to reach their goals. It is known that in the majority of schools, game and game-like elements already exist. Research on games reveals that gamification has a high potential to support people's motivation and commitment in the field of education (Fiş Erümit, 2016).

In this context, it is thought that the game-based learning environments will provide more effective learning, will increase the flow levels of students in the learning process and will positively influence student's motivation towards the course.

It has been determined that the applications developed based on gamification of teaching and the experimental studies related to these applications are insufficient.

In this research, the question "What are student opinions on QuizGame application developed on the basis of gamification-based teaching in associate degree level, Graphic Animation 1 course" will be searched.

Methods: In this research, it is aimed to reveal the current state of mobile QuizGame application used in Graphics and Animation 1 course. In this respect, this research is a descriptive survey study. The study group of the research is Çukurova University Adana Vocational School of Higher Education, 1st grade Computer Programming students who are also enrolled to Graphics and Animation 1 course. The data were gathered through the form developed in the form of a five-point Likert scale from the literature to determine student opinions. Expert opinions were received from the point of view of the suitability of the form questions. Frequency and mean values are given in the analysis of the data.

Results: It is noteworthy that the students are generally evaluating positively about the content. It is supported by the average of each item in the obtained findings. In addition to positive reviews, a small number of students indicated that there is a need to reorganize the transition rules between mobile QuizGame levels.

In terms of the installation and usage characteristics, the students responded positively. The fact that the averages of each item in the evaluation being at a good level also 
supports student views. In addition to the positive evaluations made by the students, a few students stated that there should be provided a student-student, student-manager type communication opportunity in the mobile application.

It has been determined that students have also evaluated positively for the compatibility features of the mobile QuizGame application. This is supported by the fact that the average scores of the students in the evaluation form are at a good level.

Discussion and Conclusions: Within the scope of the research, mobile QuizGame application has been evaluated under content, installation and usage features and compatibility. Based on the findings under the content, students reported positive opinions about the mobile application being used. According to the findings obtained from the characteristics of installation and use, students were evaluated positively. In the case of findings obtained from the compatibility features, students gave positive opinions in the evaluations. When the findings obtained from this study were examined, students' opinions were obtained that competition environment, performance graphs and leadership tables were interesting and remarkable by the students and showed positive effects on the motivation towards the course. 


\section{Kaynakça}

Ar, N. A. (2016). Oyunlaştırmayla öğrenmenin meslek lisesi öğrencilerinin akademik başarı ve ögrenme stratejileri kullanımı üzerine etkisi (Yayınlanmamış yüksek lisans tezi). Sakarya Üniversitesi, Sakarya.

Ateş, A. (2011). Eğitsel yazılım değerlendirme ölçeği: Geçerlik ve güvenirlik çalışması. Ĕ̈itim Teknolojileri Araştırmaları Dergisi, 2(1), 0-0.

Bozkurt, A. \& Genç Kumtepe, E. (2014). Oyunlaştırma, oyun felsefesi ve eğitim: Gamification. Akademik Bilişim 14 Konferansında sunulan bildiri, Mersin.

De-Marcos, L., Domínguez, A., Saenz-de-Navarrete, J., \& Pagés, C. (2014). An empirical study comparing gamification and socia lnetworking on e-learning. Computers \& Education, 75, 82-91.

Deterding, S., Dixon, D., Khaled, R., \& Nacke, L. (2011). From game design elements to gamefulness: defining gamification. Presented at the In Proceedings of the 15th International Academic MindTrek Conference, New York, USA.

Fiş Erümit, S. (2016). Oyunlaştırma yaklaşımlarının eğitimde kullanımı: Tasarım tabanlı bir araştırma (Yayınlanmamış doktora tezi). Atatürk Üniversitesi, Erzurum.

Glover, I. (2013). Play as you learn: Gamification as a technique formotivating learners. Retrieved 12.06.2017 from http://shura.shu.ac.uk/7172/1/Glover__Play_As_You_Learn_-_proceeding_112246.pdf

Gümüş, İ., \& Örgev, C. (2015). Önlisans öğrencilerinin akıllı cep telefon kullanmalarının başarı ve harcama düzeylerine olası etkileri üzerine bir çalışma. Uluslararası Kritik ve Analitik Düşünme Sempozyumunda sunulan bildiri, Sakarya.

Hamari, J., Koivisto, J., \& Sarsa, H. (2014). Does gamification work? - a literature review of empirical studies on gamification. Presented at Proceedings of the 47th Hawaii International Conference on System Sciences, Hawaii, USA.

Harrold, D. J. (2015). Game on: A qualitative case study on the effects of gamified curriculum design on student motivational learning habits (Unpublished $\mathrm{PhD}$ thesis). Robert Morris University, Pennsylvania, USA.

Kapp, K. M. (2012). The gamification of learning and instruction: Game-based methods and strategies for training and education. Hobeken, NJ: John Wiley\&Sons.

Kaya, Z. (2005). Öğretim teknolojileri ve materyal geliştirme. Ankara: Pegem A Yayıncilik.

Oblinger, D. G., \& Oblinger, J. L. (2005). Educating the net generation. Educause, Washington, DC.

Pixofun. (2016). Quizgame:Game as a service / Gamification. 04.06.2017 tarihinde http://www.pixofun.com adresinden alınd

Polat, Y. (2014). A case study: Gamification and its effect on motivation of learners of English (Yayınlanmamış yüksek lisans tezi). Çă̆ Üniversitesi, Mersin.

Prensky, M. (2001). Digital natives, digital immigrants. On the Horizon, 9(5), 1-6.

Prensky, M. (2004). Use their tools! Speak their language. Connected, 10, 8-11. 
Sarı, A., \& Altun, T. (2016). Oyunlaştırma yöntemi ile işlenen bilgisayar derslerinin etkililiğine yönelik öğrenci görüşlerinin incelenmesi. Türk Bilgisayar ve Matematik Ĕ̈itimi Dergisi, 7(3), 553-577.

Sarıtaş, T., \& Yıldız, Ö. (2015). Eğitimde oyunlaştırma (gamification) ve ters-yüz sınıflar. Akademik Bilişim 2015 Konferansında sunulan bildiri, Eskişehir.

Şahin, T. Y. ve Yıldırım, S. (1999). Öğretim teknolojileri ve materyal geliştirme. Ankara: Anı Yayıncılık.

Uğur, A. K. (2010). Yapısalcı öğrenme kuramına göre hazırlanan analog elektronik dersi yazılımının akademik başarıya etkisi (Yayınlanmamış yüksek lisans tezi). Çukurova Üniversitesi, Adana.

Werbach, K., \& Hunter, D. (2012). For the win: How game thinking can revolutionize your business. Philadelphia: Wharton Digital Press.

Yıldırım, İ. (2016). Oyunlaştırma temelli "Öğretim ilke ve yöntemleri” dersi ögrretim programının geliştirilmesi, uygulanması ve değerlendirilmesi (Yayınlanmamış Doktora Tezi). Gaziantep Üniversitesi, Gaziantep.

Zichermann, G., \& Cunningham, C. (2011). Gamification by design: Implementing game mechanics in web and mobile apps. Sebastopol, CA: O'Reilly Media, Inc.

Zichermann, G. \& Linder, J. (2010). Game-based marketing: Inspire customer loyalty thorugh rewards, challenges, and contests. Hobeken, NJ: John Wiley\&Sons, Inc. 